\title{
The Effect of Recast vs. Clarification Request as Two Types of Corrective Feedback on Iranian Intermediate EFL Learners' Structural Knowledge
}

\author{
Zahra Ghariblaki \\ ELT Department, Faculty of Persian Literature and Foreign Languages, Roudehen Branch, Islamic Azad University, \\ Roudehen, Iran \\ Mahpareh Poorahmadi \\ ELT Department, Faculty of Persian Literature and Foreign Languages, Roudehen Branch, Islamic Azad University, \\ Roudehen, Iran
}

\begin{abstract}
The present study, considering Form-Focused Instruction as the theoretical framework f the study, is an attempt to study the benefits of two types of teacher feedback in structural knowledge. In the current study, in the two experimental groups, students were taught syntactic items. One of these classes was offered recast as the main feedback type. The other groups offered clarification request feedback. Later the outcome of these groups compared to one another and to the control group who did receive no feedback on their structural knowledge errors. The participants in this study included three groups of Intermediate level English language learners from intact classes of Marefat Language Institute. The selected students were sampled based on their scores on PET proficiency test. In the main study 90 students (30 students in clarification request group, 30 students in oral feedback group, and 30 students in the control group) were selected out of 120 students based on the homogeneity test. Students in the clarification request group and oral feedback group received the related treatment while students in the control group received regular planning. The result of statistical analysis (ANOVA) suggested that recast group and clarification request group outperformed the control group and the clarification group outperformed the recast group.
\end{abstract}

Index Terms - corrective feedback, recast, clarification request, structural knowledge

\section{INTRODUCTION}

Feedback may be considered as one of the important ways in which syntax can be put into practice. Feedback in general has been defined as "any information that provides information on the result of behavior" (Richards \& Schmidt, 2013, p.217). They additionally note that in teaching a second language, the term feedback, refers to the comments or other information that learners receive concerning their success on learning tasks or tests, either from the teacher or other person. The term feedback sometimes has been considered as corrective feedback. This is a type of feedback in which the learners receive comments and information from a competent interlocutor. This interlocutor may be his/her teacher, peer, or parents. Corrective feedback shows that a second language learner is deviated from the correct use of the target language.

Recasts, on the other hand, are implicit, since they do not point out the error explicitly. Recast in second language acquisition has been defined as "a type of negative feedback in which a more competent interlocutor (parent, teacher, native-speaking interlocutor) rephrases an incorrect or incomplete student utterance by changing one or more sentence components (e.g. Subject, verb, or object) while still referring to its central meaning." (Richards \& Schmidt, 2013, p. 487).

Recent research in the realm of second language teaching has been overwhelmed with contradictory arguments for and against the provision of feedback to learners in second language classes. While different and abundant research has been conducted to investigate the effectiveness of corrective feedback in the different contexts of EFL, there are still arguments on the effect of different kinds of corrective feedback on EFL learners' English achievement.

Regarding the importance of corrective feedback, it seems that not very studies have been done in our country on this aspect of language learning and teaching. Meanwhile, corrective feedback can be an important instrument for facilitating the acquisition and improving syntactic accuracy. In doing so, this study aims to investigate the effect of two different but crucial kinds of feedback namely, clarification request and recast on the intermediate EFL Learners' syntactic knowledge.

The present study, considering Form-Focused Instruction as the theoretical framework $f$ the study, is an attempt to study the benefits of two types of teacher feedback in structural knowledge. Form-Focused Instruction or Focus on Form that draws students' attention to form is an approach to language teaching proposed by Long's interactional approach. In this approach, the focus is on the grammatical form of language features communicatively. Ellis (2001) 
makes a distinction between Form-Focused Instruction and Focus on Forms. In 'Focus on Forms' the focus is solely one explicit language features but in "Focus on Form" language learners are made aware of syntactical features of the language communicatively.

In the current study, in the two experimental groups, students were taught syntactic items. One of these classes was offered recast as the main feedback type. The other groups offered clarification request feedback. Later the outcome of these groups compared to one another and to the control group who did receive no feedback on their structural knowledge errors. In this study, considering the two types of feedbacks (recast and clarification request) as the independent variable of the study and learners' grammatical knowledge scores as the dependent variable, the researcher aimed to investigate the effectiveness of the two types of corrective feedback on grammar instruction. The findings of this comparison hoped to shed light on which of these two feedback types are far beneficial to enhance syntactic knowledge of the learners.

A substantial body of research in SLA has been devoted to the role of classroom interaction in second language acquisition. However, comparing the two types of feedback namely, clarification request feedback and recast feedback is an intact area of research, especially in the Iranian context. Corrective feedback is among the techniques which are believed to facilitate L2 development by providing learners with both positive and negative evidence (Long, 2003). It is as one of the effective focus on form and meaning techniques that have been employed so long to prompt the learners on focus on syntactic features and meaning in L2 classroom.

This study is an attempt to provide the intermediate EFL Iranian learners and teachers with a better understanding of which type of corrective feedback is more beneficial in teaching syntactic rules. The students receive two kinds of corrective feedback, namely recast and clarification request, by focusing on these two kinds of feedback in second language classrooms; this research claims that the differential effectiveness of these two feedbacks has a great research value, because of the following reasons,(1) theoretically, providing the data in the area of these two feedbacks can inform the issues such as the cognitive roles and processing of recast and clarification request feedback in the area of learning syntactic features of the second language,(2) pedagogically, the findings of this research will be useful for the language teachers in giving advice concerning the learners' classroom error correction in promoting the learners syntactic knowledge. This study test the interactional approach to SLT developed by Long (1989). It also tests the conductive teaching in an Iranian context. Considering practical aspect, this study explains how both teaching and learning can benefit from corrective feedback in developing learners' structural knowledge.

To fulfill the purpose of the study, the following research hypotheses were proposed:

To systematically investigate the proposed questions, the following null hypotheses are also formulated.

1. Clarification request does not have any significant effect on Iranian intermediate EFL learners' structural knowledge.

2. Recast does not have any significant effect on Iranian intermediate EFL learners' structural knowledge.

3. There is not any significant difference between the effect of clarification request and recast on Iranian intermediate EFL learner's syntactic knowledge.

\section{METHOD}

This study aimed to investigate the effect of two different but important kinds of corrective feedback namely, clarification request and recast on the intermediate EFL Learners' structural knowledge. The variables of the study included various types of feedback (independent variable) and Iranian EFL Learners' structural knowledge (dependent variable).

\section{A. Participants}

The participants in this study included three groups of Intermediate level English language learners from intact classes of Marefat Language Institute. The selected students were sampled based on their scores on PET proficiency test. Totally, 90 intermediate level language learners were homogenized using PET proficiency test. These students were assigned to two experimental groups and one-control group. That is 30 students were in each group. All of the participants had the same level of proficiency, they also had the same native language and received an equal amount, type and length of instruction during the treatment phase.

\section{B. Instrumentation}

\section{A). PET}

Cambridge English: Preliminary, also known as the Preliminary English Test (PET), is an English language examination provided by Cambridge English Language Assessment Preliminary is designed to show that a learner can use their English language skills in everyday situations when working, studying and traveling.

\section{B). Teacher made structure tests}

For the pre-test and post-test, the structure questions of the first five units of TopNotch 3 was used to assess the structural knowledge of the students before and after the treatment sessions. It was administered to measure the participants' pre and gained structural knowledge to investigate the differential effects of recast two kinds of corrective 
feedbacks. The pretest and post-test for three groups were the same regarding their contents and equivalent form but not completely equal.

C). Pre-test

This test was composed of 45 items based on the first five chapters of TopNotch intermediate English book. This test was used to measure students' structural knowledge before the treatment. After piloting the test among 20 participants those problematic items were identified based on reliability test and item discrimination index. The final remaining was a test with 40-structure questions. The reliability index of the test was.79.

\section{D). Post-test}

The same procedures were taken for another 45-item test which was based on the first chapters of TopNotch intermediate English book to construct posttest items. After piloting the tests among 20 intermediate level English language learners, the problematic items were identified, and finally, 40 items remained as the post-test. The reliability index of the test was found to be .81 .

\section{E). Instructional materials}

Based on the Pearson Longman website, TopNotch is an award-winning communicative course for adults and young adults that set new standards for reflecting how English is used as an international language.

\section{Design}

Quasi-experimental design is thought to be the most appropriate design for the present study since the sampling was not random. This study was a pretest-treatment-posttest for two experimental groups while the third group served as the control group without specific treatment.

\section{Procedures}

To measure overall English proficiency of students, (PET) which is the second level of Cambridge examinations in English for Speakers of Other Languages (ESOL) was used.

In the main study 90 students (30 students in clarification request group, 30 students in oral feedback group, and 30 students in the control group) were selected out of 120 students based on the homogeneity test. Students in the clarification request group and oral feedback group received the related treatment while students in the control group received regular planning. The following procedures were conducted in the two experimental groups.

\section{First group: Recast}

\section{Session 1}

At the first session in recast class, the purpose of the study, the procedures and ethical issues were introduced to students. At this session, the researcher took pre-test which was a teacher-made test and piloted it on 30 students to measure their structural knowledge.

\section{Session 2}

At first the researcher taught tag question grammar and asked the students to do the exercises related to this grammar, in the recast class, the teacher asked the students to do pair work and having interaction with each other and when the students were doing exercises, the teacher recast when they made a mistake like:

1 .S. Robert Roston is the director of English program, doesn't he?

\section{T: doesn't he? Isn't he?}

S: yes isn't he?

Then the teacher asked them to look at the picture in conversation pair work and make small talk as pair work. When they did the exercises, the teacher gave isolated declarative recast to the related grammatical mistakes. A sample from their mistakes and the teacher's recast feedbacks are provided in the following.

1. S: We have met each other before, didn't we?

T: Haven't we?

S: yes, haven't we?

The teacher, furthermore, asked the students to have a role play according to the exercise in their workbook in which there were two people talking with each other. The focus of the exercise was on using tag questions in small talks. This is a sample from the students' sentences and the teacher's isolated declarative recasts. Such as:

1. S: We have met each other before, didn't we?

T: Haven't we?

S: yes, haven't we?

The researcher wrote this situation on the board for more practice, and the researcher asked the students to read that situation and make sentences about that situation and use tag questions. The researcher writes this situation on the board.

Your friend got good grades on her science test.

Moreover, the researcher asked the learners to make sentences. They made the following sentences, and the researcher gave recast on their grammatical mistakes.

1. Today is Saturday, is it?

T. is it?

S. isn't it.

\section{Session 3}


At the 4th session in the recast class, at first, the researcher asked the students to have a conversation with each other and to use tag questions and to have role play and interaction with each other, and they did it.

Then the researcher taught past perfect grammar and asked the students to do the exercises related to past perfect. Based on the learners' answers the teacher gave recast as the implicit provision of correct reformulation of the student's ill-formed utterance on their grammatical mistakes. Then the teacher asked learners to look at the table and to do the exercises, and the researcher gave recast on their grammatical mistakes.

For example:

1. S: At 8:30 Lyne had dropped off her jacket, but she didn't yet taken the cats to Mara's house.

T: she didn't yet taken the cats?

S: She hadn't yet taken the cats to Mara's house. (Recast)

The researcher wrote another question on the board in the recast class for more practice, and the researcher asked the students to use past perfect for answering this question. The question was as follows:

What had you accomplished by 2013?

Moreover, they gave different answers and the researcher gave recast on their grammatical mistakes like:

1. S. By 2012 I got my Diploma.

T. You got your Diploma. You had got your Diploma.

S. Yes, I had got my Diploma.

\section{Session 4}

At first in the 5th session in the recast class, the researcher asked the students to do the exercises of the book, and then the researcher gave recast on their grammatical mistakes while doing the exercises in the recast class like:

S. You are not from around here, aren't you?

T. Aren't you? Are you?

S. Yes, aren't you? (Uptake)

Then the researcher asked them to look at pictures of the book and to make conversation and have interaction with each other regarding the pictures and use tag questions in their small talks and provided recast feedback in the class. Students also were requested to have interaction during the activity.

Such as:

S: It's a good place for traveling, is it?

$\mathrm{T}$ : is it?

S: Isn't it?

Then the researcher taught the grammar (may, might, must and be able to) and then asked the students to do the exercises which was related to this grammar and to use may and might in this exercise. The researcher, then, provided recast on their grammatical mistakes when they were doing this exercise like:

1. T. When will you practice English outside the class?

S. I must practice English tomorrow morning.

T. You may practice English tomorrow morning

S. Oh,

\section{Session 5}

In recast class, after teaching causative get, have and make on page 30, the researcher asked the students to make sentences using causative get and these are the sentences they made and I gave recast feedback on their grammatical mistakes such as:

1. S.I got my friend copy the report for me.

T. I got my friend to copy the report for me. (Recast)

S. sorry, yes, .I got my friend to copy the report for me. (Uptake)

We use make to suggest an obligation and use make with an object and the base form of the verb.

Moreover, the researcher asked them to make sentences by using causative make, and I gave incorporative interrogative recast on their grammatical mistakes.

S. she made me to reserve the hotel.

T. she made you what? (Recast)

S. sorry, she made me reserve the hotel. (Uptake)

2. Experimental group 2: Clarification Request

\section{Session 1}

At the first session in clarification request group, the purpose of the study, the procedures and ethical issues were introduced to students. At this session, the researcher took pretest which was a teacher-made test and piloted it on 30 students to measure their structural knowledge.

\section{Session 2}

In clarification request class, at first, the teacher taught tag question grammar and the teacher asked the students to do the exercises related to this grammar. When they were doing exercises, the teacher gave clarification request feedback on their grammatical mistakes. This is a sample of their mistakes and the teachers' clarification request feedback.

1. Robert is the director of the English program, does he? 
T. Sorry, I don't understand?

S. Robert is the director of the English program, isn't he?

Then the researcher asked them to look the picture in conversation pair work part of the book and to make small talk and interaction as pair work with them. They did the exercise, and the teacher gave clarification feedback on their mistakes. This is a sample of their mistakes and the provided clarification request feedback:

1. S. You are staying in Tehran, don't you?

T. would you please repeat again? (Clarification request feedback)

S. You are staying in Tehran, don't you? (Uptake)

In clarification request class, the teacher asked the leaners to look at the same picture in which two people were talking to each other and asked them to imagine that they were these two ones and to have interaction with a role play with each other. They have to use tag question in their small talks, and the teacher provided clarification request feedback on their grammatical mistakes. This is a sample of the sentences students made and the clarification request feedback such as:

1. S. It's not 3:30 yet, is it?

T. What do you mean?

S. It's not 3:30 yet, is it?

\section{Session 3}

In this session, the teacher taught causative get, have and make and asked the students to make sentences using causative get/have. These are the sentences they made and the teacher gave clarification request feedback on their grammatical mistakes such as:

1. S. They can have the film process.

T. Would you please repeat your sentence?

S. They can have the film processed.

Then the teacher explained causative made and said that we use make to suggest an obligation. Then the teacher asked the learners to make sentences and use causative make.

This is a sample of the sentences they made and the related clarification request feedback on their grammatical mistakes such as:

1. I made my aunt to make food.

T. Would you repeat your sentence please?

S. I made my aunt make food.

\section{Session 4}

In this session, after teaching future in past grammar, the teacher asked the students to do the exercises related to this grammar in the book in which they were asked:

They compared the plans and beliefs they had about their future when they were young.

The students did the exercise, and the teacher gave clarification request feedback on their grammatical mistakes such as:

S. When I was young I thought I would finished my University.

T. what?

S. When I thought I would finished my University.

Then the teacher taught the grammar on page 42 perfect modals, expressing regrets about the past with should thave $+\mathrm{pp}$ and would thave $+\mathrm{pp} /$ may +have $+\mathrm{pp} /$ might + have $+\mathrm{pp}$ for speculating about the past and must +have+ $\mathrm{pp}$ for drawing the conclusion about the past. And I asked them to do the exercise of the book which was related to this grammar.

In that exercise, the teacher asked them to share their regrets and tell their partners what they regret about their life , their studies, their work, or their actions in the past and use should have or shouldn't have and would have/ might have/ may have $+\mathrm{pp}$. Then the teacher provided them recast with their grammatical problems.

When they were doing exercises the teacher gave clarification request feedback on their grammatical mistakes. These are the clarification request feedbacks:

1. A. I should have married marry.

B. why?

A. I would have be a good husband.

T. would you repeat again?

A. I would have been a good husband.

Then in the class, according to the book exercise, in which there were sentences and asked the students to provide reasons for these sentences and to use perfect modals grammar. The teacher wrote one of those sentences and asked them to provide reasons for each of these sentences and to use perfect modals in their reasons. At first, the teacher wrote this sentence.

All the students failed the exam

Then the teacher asked the learners to provide grounds for each of these sentences and speculate with may have / might have / may not have / might not have or draw conclusions with must have / must not have. 
They made the following sentences:

S1. They don't have studied hard.

T. They what?

S1. They wouldn't have studied hard.

Session 5

In this session in clarification request feedback class, the teacher asked the following question from students:

What they think might have happened if they had been a doctor?

They gave different answers and used perfect modals grammar in their answers and the teacher gave clarification request feedback on their grammatical mistakes. The following is one sample from the session:

S.I would be happier.

T. what?

S. I would have been happier.

The teacher taught adjective clause with subject relative pronouns and after doing the exercises which were related to this grammar, the teacher asked them to create five sentences with adjective clauses to describe some holidays in their country. They did this exercise as pair work. While doing the exercises as pair work, the clarification feedback was provided.

S. There is a man which celebrates the harvest each month.

T. what?

S. There is a man who celebrates the harvest each month.

In clarification request feedback class, the teacher asked them to make sentences with adjective clauses with a subject relative pronoun. I gave clarification request feedback on their grammatical mistakes. These are the sentences students made and my feedbacks.

1 .S. The film you bought gives you great information.

T. What?

S. The film that you bought gives you great information.

\section{Session 6}

In this session, in clarification request feedback class, I asked the students to make sentences with adjective clauses (relative pronoun is the subject of the clauses).

When they were doing exercises, the teacher gave clarification request feedback on their grammatical mistakes. These are the clarification request feedback that the teacher gave:

1. S. The film you bought gives you great information.

T. What?

S. The film that you bought gives you great information.

Then the teacher explained relative pronouns as the object of the clause, and the teacher asked the students to do the exercises of the book which was related to this grammar and then the teacher asked the students to make sentences and to use a relative pronoun as the object of the clause. They made these sentences, and the teacher gave clarification request feedback on their grammatical mistakes as follows:

1. S. The man who you talked to is my brother.

T. What?

S. The man whom you talked to is my brother.

Then in clarification request class, I asked the students to make sentences about the picture at the end unit 5 which was about red pepper festival and to use adjective clauses in their sentences. They made the sentences and the teacher gave clarification request feedback on their grammatical mistakes such as:

1. S. There are two boys are laughing with each other.

T. "sorry."

S. There are two boys who are laughing with each other.

\section{Group 3 the Control Group}

At the first session in the control group, the purpose of the study, the procedures and ethical issues were introduced to students. At this session, the researcher took pretest which was a teacher-made test and piloted it on 30 students to measure their structural knowledge.

In control group class, grammatical points (such as tag questions) were taught as inductively and then the teacher asked the students to do the exercises related to this grammar. The teacher gave no feedback while they were doing the exercises and the teacher corrected their grammatical mistakes ordinarily.

Practicing grammar in conversation was one of the regular activities in the control group.

For instance, the teacher asked the students to look at the picture on conversation pair work part and ask the students to have interaction with each other and make small talks as pair work about the picture and its subjects. They did the exercises, and the teacher gave no feedback on their mistakes and corrected their grammatical mistakes ordinarily. Then the teacher asked the students to the exercises in the workbook which was related to this grammar in which there was a picture, and two people were talking. The teacher asked the students to have role play about it and to use tag questions 
in their small talks. They did the exercises, however in this group as the control group the teacher gave no feedback on their mistakes, and she corrected their grammatical mistakes ordinarily.

For more practice, the teacher wrote the following situation on the board and asked the students to read the situation and to make sentences about that situation and to use tag questions in their sentences.

The teacher wrote the following situation:

Your friend got good grades on her science test

They made these sentences, and the teacher gave no feedback on their mistakes and corrected their grammatical mistakes ordinarily.

\section{RESUlTS AND DisCUSSIONS}

After homogenizing the students regarding language proficiency, a pretest was given to the participants to assure that the participants did not have prior knowledge of the content of the materials to be taught before the treatment. The results of students' scores on pre-test are reported in the table below.

TABLE 1:

DESCRIPTIVE STATISTICS FOR THE PRE- TEST

\begin{tabular}{|c|c|c|c|c|c|c|}
\hline \multicolumn{7}{|c|}{ DESC } \\
\hline & & $\mathrm{N}$ & Minimum & Maximum & Mean & Std. Deviation \\
\hline \multirow[t]{2}{*}{ RecastG } & pretest & 30 & 6.00 & 19.00 & 12.20 & 3.73 \\
\hline & Valid N (listwise) & 30 & & & & \\
\hline ClarificationRG & pretest & 30 & 7.00 & 25.00 & 15.10 & 4.16 \\
\hline \multirow[t]{2}{*}{ ControlG } & pretest & 30 & 6.00 & 19.00 & 12.4333 & 3.39049 \\
\hline & Valid N (listwise) & 30 & & & & \\
\hline
\end{tabular}

\section{A. Pretest}

The one-way analysis of variance (ANOVA) was used to determine whether there is any significant difference between the means of three groups (Recast group, Clarification request group, and control group) in the pretest. There are some assumptions to run ANOVA test.

TABLE 2:

DESCRIPTIVE FOR ANOVA (PRETEST)

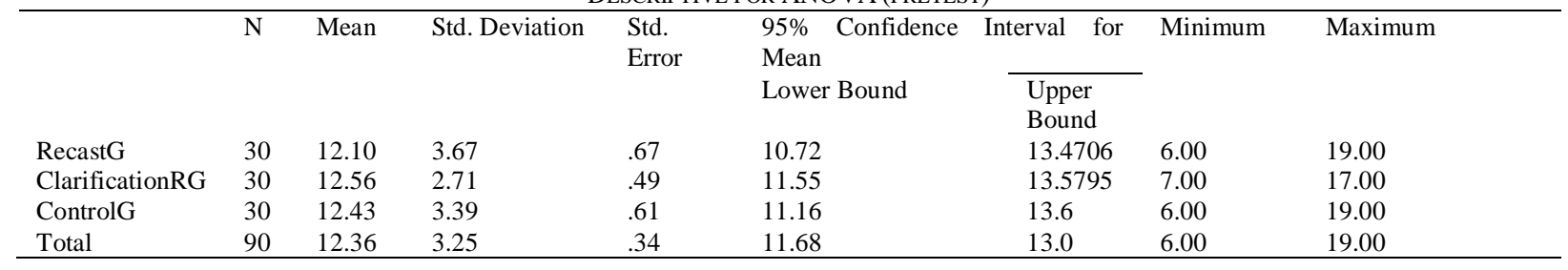

This is the table that shows the output of the ANOVA analysis and whether we have a statistically significant difference between our group means. We can see that the significance level is $0.06(\mathrm{p}=.06)$, which is above 0.05 . Moreover, therefore, there is not a statistically significant difference in the mean score of the groups in the pre-test. Therefore, the students in all group were homogenized in structural knowledge before the instruction.

TABLE 3:

ANOVA PRE-TEST

\begin{tabular}{llllll}
\hline & & & & Sig. \\
Between Groups & Sum of Squares & df & Mean Square & F & .16 \\
Within Groups & 3.46 & 2 & 1.73 & & .85 \\
Total & 937.43 & 87 & 10.77 & & \\
\hline
\end{tabular}

\section{B. Post-test}

\section{Hypothesis One:}

1. Do providing clarification request feedbacks have any significant effect on Iranian intermediate EFL learners' syntactic knowledge?

H01: Providing clarification request does not have any significant effect on Iranian intermediate EFL learners' syntactic knowledge.

To test the mentioned hypothesis an independent sample, a t-test was used. The independent-sample t-test compares the means between two unrelated groups on the same conditions. One of the two groups were (Recast G, and Control G), and the other was (Clarification $\mathrm{G}$, and Control $\mathrm{G}$ ).

Considering all of the mentioned assumptions, the result of the post-test analysis is reported in the following tables. 


\begin{tabular}{llllll}
\multicolumn{5}{c}{ TABLE 4: } \\
& \multicolumn{5}{c}{ GROUP STATISTICS } \\
\hline \multirow{3}{*}{ posttest } & group & $\mathrm{N}$ & Mean & Std. Deviation & Std. Error Mean \\
& ClarificationRG & 30 & 25.8667 & 4.19962 & .76674 \\
& ControlG & 30 & 20.2333 & 4.64375 & .84783 \\
\hline
\end{tabular}

As the table of descriptive statistics show the mean of clarification request group $(M=25.86$, Std. Deviation. $=4.19)$ was more than that of the control group $(M=20.23$, Std.Deviation=4.64).

TABLE 5:

INDEPENDENT SAMPLES TEST

\begin{tabular}{|c|c|c|c|c|c|c|c|c|c|c|}
\hline \multirow{4}{*}{ posttest } & \multirow{4}{*}{$\begin{array}{l}\text { Equal variances } \\
\text { assumed } \\
\text { Equal variances } \\
\text { not assumed }\end{array}$} & \multicolumn{2}{|c|}{$\begin{array}{l}\text { Levene's Test } \\
\text { for Equality of } \\
\text { Variances }\end{array}$} & \multicolumn{7}{|c|}{ t-test for Equality of Means } \\
\hline & & $\mathrm{F}$ & Sig. & $\mathrm{t}$ & df & $\begin{array}{l}\text { Sig. (2- } \\
\text { tailed) }\end{array}$ & $\begin{array}{l}\text { Mean } \\
\text { Difference }\end{array}$ & $\begin{array}{l}\text { Std. Error } \\
\text { Difference }\end{array}$ & \multicolumn{2}{|c|}{$\begin{array}{l}95 \% \text { Confidence } \\
\text { Interval of the } \\
\text { Difference }\end{array}$} \\
\hline & & .000 & .99 & 4.98 & 58 & .01 & 5.63 & 1.14 & $\begin{array}{l}\text { Lower } \\
3.34\end{array}$ & $\begin{array}{l}\text { Upper } \\
7.92\end{array}$ \\
\hline & & & & 4.92 & 57.42 & .01 & 5.63 & 1.14 & 3.34 & 7.92 \\
\hline
\end{tabular}

As the table of independent sample t-test shows there was a significant difference in the mean score of clarification request group $(M=20.23$, Std.Deviation=4.64), and that of control group $(M=20.23$, Std.Deviation= 4.64) at $t(58)=$ 4.92, $\mathrm{p}=.01$ ), suggesting that the null hypothesis was rejected, that is recast group outperformed the control group.

Hypothesis two:

Do providing recasts have any significant effect on Iranian intermediate EFL learners' syntactic knowledge?

Providing recast does not have any significant effect on Iranian intermediate EFL learners' syntactic knowledge.

TABLE 6:

\begin{tabular}{llllll}
\multicolumn{5}{c}{ GROUP STATISTICS } \\
\hline & group & $\mathrm{N}$ & Mean & Std. Deviation & Std. Error Mean \\
\hline posttest & RecastG & 30 & 23.76 & 4.78 & .87 \\
& ControlG & 30 & 20.23 & 4.64 & .84 \\
\hline
\end{tabular}

As the table of descriptive statistics show the mean of recast group $(M=23.76$, Std. Deviation. $=4.88)$ was more than that of the control group $(M=20.23$, Std. Deviation= 4.64).

TABLE 7:

INDEPENDENT SAMPLES TEST

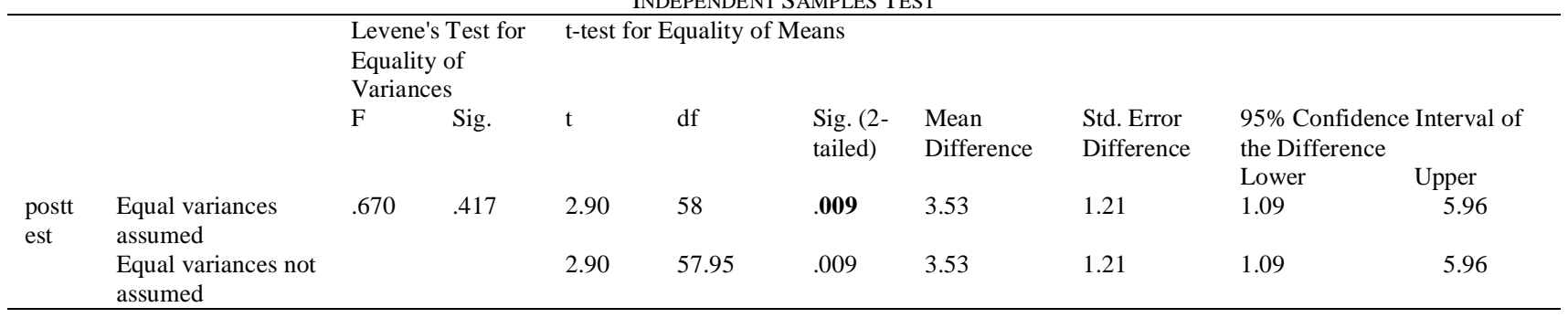

As the table of independent sample t-test shows there was a significant difference in the mean score of the recast group $(M=20.23$, Std.Deviation= 4.64), and that of control group $(M=20.23$, Std.Deviation= 4.64) at $t(58)=2.90$, $\mathrm{p}=009$ ), suggesting that the null hypothesis was rejected, that is the clarification group outperformed the control group.

Hypothesis Three:

Is there any significant difference between the effect of clarification request feedbacks and recast feedbacks on Iranian intermediate EFL learners' syntactic knowledge?

H03:

3. There is not any significant difference between the effect of clarification request and recast on Iranian intermediate EFL learner's syntactic knowledge.

\begin{tabular}{llllll}
\multicolumn{5}{c}{ TABLE 8: } \\
& \multicolumn{5}{c}{ GROUP STATISTICS } \\
\hline \multirow{3}{*}{ posttest } & group & $\mathrm{N}$ & Mean & Std. Deviation & Std. Error Mean \\
& RecastG & 30 & 23.76 & 4.78 & .87 \\
& ClarificationRG & 30 & 25.86 & 4.19 & .76 \\
\hline
\end{tabular}

As the table of descriptive statistics show the mean of clarification request group $(\mathrm{M}=25.76$, Std. Deviation. $=4.78)$ was more than that of recast group $(M=23.76$, Std.Deviation=4.78). 
TABLE 9:

INDEPENDENT SAMPLES TEST

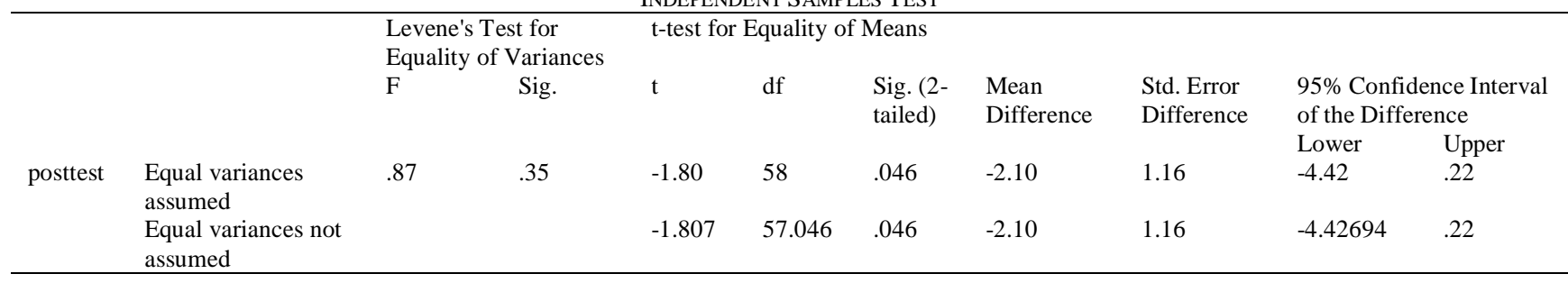

As the table of independent sample t-test shows there was a significant difference in the scores of clarification request group $(M=25.76$, Std. Deviation. $=4.78)$, and recast group $(M=23.76$, Std. Deviation= 4.78). at $t(-1.80)=2.90$, $\mathrm{p}=046)$, suggesting that the null hypothesis is rejected, that is the clarification group outperformed the recast group.

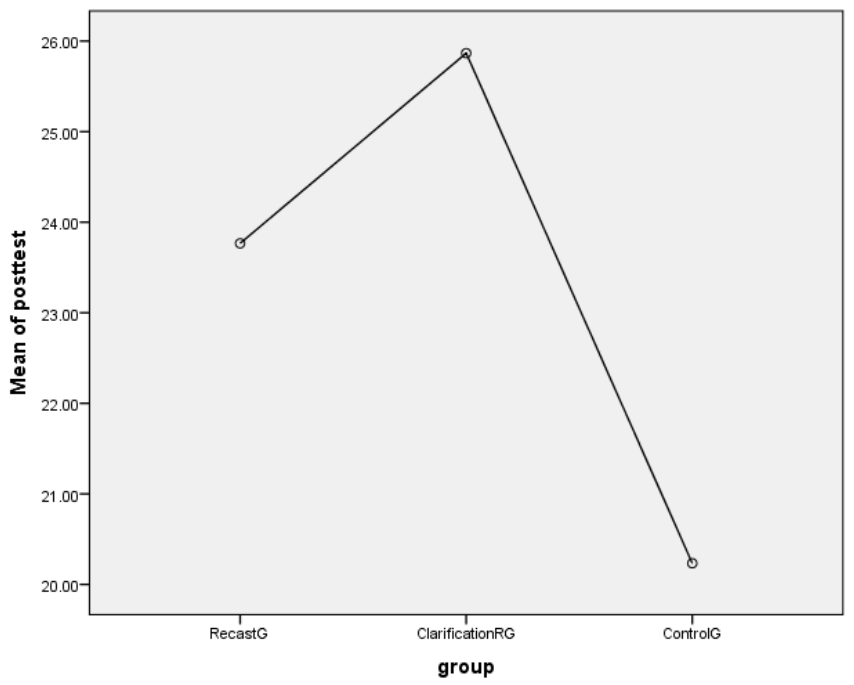

Figure 1: students post-score in three group

The results of the current study indicated that the first and the second null hypothesis were rejected, and alternative hypotheses were accepted. That is to say, implementing clarification request strategies and recast positively affect student's structural knowledge. Furthermore, the third null hypothesis is rejected, since there was a significant difference between the effect of clarification request and recast on Iranian intermediate EFL learner's structural knowledge and the clarification request outperformed the recast.

The finding of the study mostly confirmed some of the related studies in the literature. The finding of the current study was in line with the findings of Ding (2012) on the role of recast in developing the linguistic feature. Ding (2012) argued that recasts can be a beneficial tool in encoding different kinds of knowledge (declarative and procedural). This was actually as one of the areas of research interest $f$ in studying the effectiveness of corrective feedback. The current study, as an empirical study of the related field, proved that these claims can be generalized to an EFL setting (Iranian context).

This study like the previous studies found corrective feedbacks effective in eliminating possible erroneous structures in the learners' interlanguage. In other words, in response to the question whether to correct or not we can say that leaving the errors unnoticed might result in the fossilization of these erroneous structures. Hence, the researcher stood against too much error negligence and subsequently believes that errors should be corrected either on the spot as in this study or with delay.

Given the significance of syntax, learning and teaching it seem to be considerably important in the process of foreign language learning. Feedback could be assumed as one of the important ways in which syntax can be put into action. It sometimes has been considered to be as corrective feedback, a type of feedback in which the learners receive comments and information from a competent interlocutor (e.g., his/her teacher, peer, or parents). Corrective feedback shows that a second language learner is deviated from the correct use of the target language.

Feedbacks provided through clarification requests were more effective than those of recast, and the mean difference between the two groups was significant at the posttest. The reason may be resulted from the fact that the clarification request feedback may be provided to the learners more interactively. Ellis et al. (2003) argued that these interactions can be beneficial to the students in some ways. Firstly, it helps students to receive comprehensible input, it also helps learners with negative feedback, and finally it prompts learners to reformulate their utterances.

\section{CONCLUSION}


There may be some pedagogical implications for these kinds of studies. It should be noted drawing a generalizable pedagogical implication from a single study may be somehow erroneous. However, there are some stakeholders who may benefit from this study. First of all, syllabus designer and specialists in material development Syllabus designers can incorporate different kind of tasks involving different kinds of feedbacks in their syllabus. This study confirmed that providing and corroborating feedback to learners' erroneous utterances have significant effects on the elimination of such erroneous structure from the learners' interlanguage. Among the different feedback types, the current study focused on recast and clarification request. The examples and prompts used in the current study can be productive examples to be used in teaching grammar.

The results of this study can also be useful for teacher training courses. Teacher trainers may inculcate certain types of interactional teaching and providing feedbacks to their trainees.

The current study had some limitations. First of all, the participants in this study were from intact classes at Marefat language institute. Hence, the generalizability of this study to the larger population might be questioned. Then, the study was limited to investigate intermediate learners. The final limitation of the study was related to the design of the study. The design of the study was quasi-experimental; therefore random sampling was not possible. To have an accurate understanding of the effect of the effect of recast and clarification feedback on the Iranian EFL learners' syntactic knowledge we should have complete randomization.

Some suggestions for further research can be proposed based on this study and the related studies in the literature. This study is exclusively focused on the role of corrective feedback in grammar instruction. Other researchers can investigate the effect of corrective feedback in other areas of language learning like interlanguage pragmatics development. Corrective feedback and the learner's uptake is another line of research for interested researchers. Interested researchers can explore the effect of different kinds of feedback on learner's uptake.

\section{REFERENCES}

[1] Costa, A. L. (1991). Developing Minds: A Resource Book for Teaching Thinking. Revised Edition, Granite Bay, California.

[2] Ding, T. (2012). The comparative effectiveness of recasts and prompts in second language Classrooms. Journal of Cambridge Studies, 7(2), 83-97.

[3] Ellis, R. (2001). Introduction: Investigating Form - Focused instruction. Language learning, 51(s1), 1-46.

[4] Ellis, R. (2003). Task-based language learning and teaching. Oxford University Press. Blackwell.

[5] Ellis, E., Axelson, M., Abrahamsson, A., Eggertsen, G., Thörne, A., Nowak, Einarsson, C. (2003). Feedback regulation of bile acid synthesis in primary human hepatocyt\& es: evidence that CDCA is the strongest inhibitor. Hepatology, 38(4), 930-938.

[6] Hu, G. (2003). English language teaching in China: Regional differences and contributing factors. Journal of Multilingual and Multicultural Development, 24(4), 290-318.

[7] Hyland, K., \& Hyland, F. (2006). Contexts and issues in feedback on L2 writing: An introduction. Feedback in second language writing: Contexts and issues, TESEL-EJ, 11(2) 1-19.

[8] Long, M. H., \& Doughty, C. (Eds.). (2003). The handbook of second language acquisition (pp. 487-536). Oxford, England: Blackwell.

[9] Richards, J. C., \& Schmidt, R. W. (2013). Longman dictionary of language teaching and applied linguistics. Routledge. New York.

[10] Seltzer, K., \& Bentley, T. (1999). The creative age: Knowledge and skills for the new economy. Demos. UK

[11] Wilson, J. S., \& Worsham, A. D. (1988). Combinations of nonselective herbicides for difficult to control weeds in no-till corn, Zea mays, and soybeans, Glycine max. Weed Science, 36 (5) 648-652.

Zahra Ghariblaki is a postgraduate in applied linguistics. She is teaching at Marefat Language Institute in Tehran. Her area of interests include but not limited to task-based language teaching, cooperative language teaching, scaffolding strategies in teaching language skills, motivation studies.

Mahpareh Poorahmadi holds a PhD degree in English language education. Her favorite research areas include task-based language teaching, cooperative language teaching, scaffolding strategies in teaching language skills, motivation studies, English for specific purpose (ESP), psycholinguistics and English language teaching (ELT) methodology. She has published articles in related areas. She is an assistant professor and a full time faculty member of the Department of English language at Roudehen Branch of Islamic Azad University, Iran. At present, she teaches MA and BA courses of English language Education. 